\title{
Prescribing pattern and appropriateness of drug treatment of diarrhoea in hospitalised children at a tertiary care hospital in India
}

\section{Jigar R. Panchal, Chetna K. Desai', Geetha S. Iyer', Prakruti P. Patel' ${ }^{1}$, R. K. Dikshit ${ }^{1}$}

Departments of Pharmacology, Government Medical College, Vadodara, and ${ }^{1} \mathrm{~B} \mathrm{~J}$ Medical College, Ahmedabad, Gujarat, India

Address for the Correspondence: Dr. Jigar Panchal, Department of Pharmacology, Government Medical College, Vadodara, Gujarat, India E-mail: doc.jigarpanchal@yahoo.

co.in

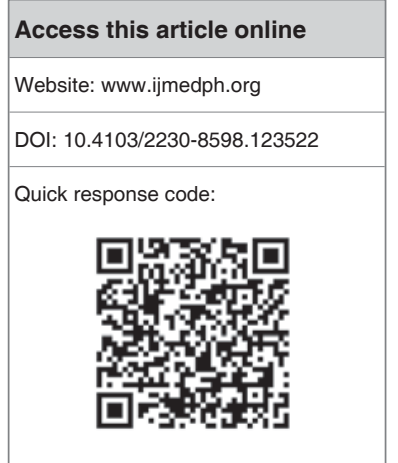

Objectives: To analyze the prescribing pattern and appropriateness of drug treatment of diarrhoea in hospitalized children. The economic burden of the disease and adverse drug reactions (ADRs) occurring during the course of treatment was also studied. Materials and Methods: It was a prospective, observational, single center study undertaken in pediatric inpatients of diarrhea, aged one month to twelve years over a period of eighteen months at a tertiary care teaching hospital in western India. Modified Kunin's criteria along with the guidelines set by the Indian Academy of Pediatrics (IAP) and WHO were followed for assessing the appropriateness of the antimicrobials prescribed. The adverse drug reactions occurring during course of the treatment were noted and the economic burden of the disease was calculated as direct and indirect costs. Results: A total of 103 patients were enrolled, of whom $45 \%$ were in the age group of one month to one year. Diarrhoea with some dehydration was diagnosed in $50.5 \%$ patients followed by severe dehydration $(34.9 \%)$ and no dehydration $(14.6 \%)$. The number of drugs and antimicrobials prescribed per patient were $7.53 \pm 1.87$ and $1.92 \pm 0.67$, respectively. Rehydration fluids $(31.6 \%)$ and antimicrobials $(25.5 \%)$ were the commonest drug groups prescribed. Among the antimicrobials, cefotaxime, cotrimoxazole and amoxicillin with clavulanic acid were frequently prescribed. Appropriate antibacterial therapy was given in only $13 \%$ of the cases. Only one ADR due to cotrimoxazole was observed. The economic burden of the disease was calculated to be Rs. 3164.81 per patient. Conclusion: Inappropriate use of antimicrobials was seen in the study. Emphasis on proper diagnosis and treatment, education and availability of locally effective guidelines may help in a better and judicious use of drugs in children.

Key words: Adverse drug reactions, Diarrhoea, drug utilization, modified Kunin's criteria, pediatric patients

\section{INTRODUCTION}

Children represent about $40 \%$ of India's population. Most suffer from frequent, usually selflimiting illnesses. Drug use in children has not been as extensively researched as in adults. It has been observed that $18.2 \%$ of children take drugs that are not required. ${ }^{[1]}$ Respiratory tract and gastrointestinal tract are the common sites for infections in children. Diarrhoea or gastroenteritis is defined as "passage of loose, liquid or watery stools more than three times a day with/without bloody stools, vomiting or dehydration". Each year 12 million children in developing countries die before they reach their 5 th birthday, many during the first year of life. Among these, $16 \%$ deaths are due to acute diarrhoeal disease. Among five children nearly one's death is due to diarrhoea, a loss of about 1.5 million lives each year. This toll is greater than that caused by AIDS, malaria and measles combined. ${ }^{[2]}$ In India, diarrhoeal disease accounts for $8.2 \%$ of total burden of disease, contributing 22 million Disability Adjusted Life Years (DALYs), the highest among communicable diseases. ${ }^{[3]}$ On an average, a child suffers from around 12 episodes of diarrhoea, 4 such episodes occurring in infancy. ${ }^{[4]}$ This has a negative impact on quality of life and can result in considerable healthcare costs. 
The pathogens causing diarrhoea are mainly viruses in children below the age of five years, while both bacterial and viral pathogens are implicated in adults. Other causes of diarrhoea are disordered motility, lactose intolerance, irritable bowel disease, bile salt enteritis, inflammatory bowel disease etc. Rotaviruses are the most common organisms (15-25\%) causing diarrhoea in children followed by bacterial pathogens like Escherichia coli (10-20\%), shigella (5-10\%), campylobacter (10-50\%), Vibrio cholerae $(5-10 \%)$ and salmonella species. The use of new low osmolarity ORS and zinc supplementation in all cases of diarrhoea in addition to breast feeding, continued feeding and selective use of antibiotics help in reducing morbidity and mortality due to diarrhoea. The WHO estimates that antibiotic treatment is necessary in only one in twenty cases of childhood diarrhoea. Yet huge resources are currently spent on anti-diarrhoeal drugs annually, most of which are useless or harmful. Therapeutic guidelines have been issued by the WHO and Indian Academic of Pediatrics (IAP), which aim at reducing the inappropriate use of antimicrobials and anti-diarrhoeal drugs in treatment of diarrhoea. The effectiveness of such guidelines can be evaluated by drug utilization research. This study was carried out to evaluate the utilization pattern of drugs prescribed for diarrhea in children admitted in a tertiary care hospital in a state of western India. The compliance with Standard Treatment Guidelines, cost and adverse reactions to drugs used in treatment of diarrhea in these patients were also evaluated.

\section{MATERIALS AND METHODS}

This was a prospective, observational, single center study, undertaken in pediatric inpatients of diarrhoea at Civil Hospital Ahmedabad (CHA), a tertiary care teaching hospital in western India. The study was carried out over a period of $18 \mathrm{~m}$. Permission from Medical Superintendent and the Head of the respective paediatric unit was obtained before conducting the study. Children aged between $1 \mathrm{~m}$ to 12 years, of either gender and diagnosed to be suffering from diarrhoea were included after consent from the parents/guardians. Demographic and clinical data obtained from these patients were recorded in pretested case record form (CRF) and analyzed to determine the utilization pattern of drugs used. The economic status of the caretakers of the patients was determined ${ }^{[5]}$ and the immunization status was determined in reference to the national immunization schedule. ${ }^{[6]}$ Modified Kunin's criteria ${ }^{[7]}$ and the guidelines of the Indian Academy of Pediatrics, India ${ }^{[8]}$ (IAP) were used to assess the appropriateness of drugs prescribed. The cases were categorized as per the following criteria:

I. Agree with the use of antimicrobial therapy; the protocol (choice, route, duration, and dosage) is appropriate.

II. Agree with the use of antimicrobial therapy; the protocol (choice, route, duration and dosage) is probably appropriate. Usually a microbiology report is missing to classify the protocol in another category.

III. Agree with the use of antimicrobial therapy; but a different antimicrobial (less expensive, less toxic, narrower spectrum, other combination) is preferred.
IV. Agree with the use of antimicrobial therapy but a modified dose, interval, duration or route of administration is preferred.

V. Disagree with the use of antimicrobial therapy, administration is unjustified.

Categories I and II indicate "appropriate therapy", categories III and IV indicate that there was some major deficiency in the choice or use of antimicrobials and category $\mathrm{V}$ indicates unnecessary antimicrobial use. The economic burden of the disease was calculated as direct and indirect cost of therapy. ${ }^{[9]}$ The adverse reaction of these drugs were noted and analyzed for seriousness and causality assessment using standard assessment scales. The data was recorded and analyzed using Microsoft Excel spreadsheet 2007. Chi-square test was used for statistical analysis and $P<0.05$ were considered to be statistically significant.

\section{RESULTS}

A total of 103 inpatients of diarrhoea were enrolled over the period of $18 \mathrm{~m}$. Out of these, $56(54.4 \%)$ were males and 47 (45.6\%) were females (male to female ratio was 1.19: 1) .The mean age of the patients was $2.77 \pm 2.84$ years with a range of $1 \mathrm{~m}$ to 11 years. Most patients $(45 \%)$ were less than 1 year of age. About $57 \%$ belonged to the lower income group (family income less than 40,000 per annum). A total of $78.8 \%$ patients were fully immunized as per the National Immunization Schedule. Pica was reported in 13 patients (12.6\%). Protein Energy Malnutrition (PEM) was observed in 42 (40.8\%) inpatients; among these 33 patients had mild to moderate malnutrition and 9 patients had severe malnutrition (Grade III and IV) [Table 1].

Out of 103 inpatients, 15 (14.6\%), 52 (50.5\%) and $36(34.9 \%)$ were diagnosed with no, some and severe dehydration, respectively

\begin{tabular}{lc} 
Table 1: Demographic and Clinical characteristics \\
of pediatric inpatients with diarrhoea $(\boldsymbol{n}=103)$ \\
\hline Patient characteristic & Number of patients (\%) \\
\hline Age & \\
$>1$ month to $\leq 1$ year & $45(43.7)$ \\
$>1$ year to $\leq 3$ years & $26(25.2)$ \\
$>3$ years to $\leq 5$ years & $12(11.7)$ \\
$>5$ years & $20(19.4)$ \\
Gender & \\
Male & $56(54.4)$ \\
Female & $47(45.6)$ \\
Immunization status & \\
Complete & $81(78.6)$ \\
Partial & $14(13.6)$ \\
Nonimmunized & $7(6.8)$ \\
Unknown & $1(0.97)$ \\
Status of dehydration & \\
No dehydration & $15(14.6)$ \\
Some dehydration & $52(50.5)$ \\
Severe dehydration & $36(34.9)$ \\
\hline
\end{tabular}


[Table 1]. On stool examination, infection with Vibrio cholerae was detected in 5 patients and with E.coli in 4 patients while stool examination was negative for pathogens in the remaining patients. Anaemia, severe malnutrition and septicaemia were observed in 64, 9 and 5 patients respectively. The average duration of diarrhoea was $2.31 \pm 1.63$ days in inpatients with a frequency of 4 to 15 diarrhoeal episodes per day. Out of 103 inpatients, 99 patients were cured and discharged, while 2 patients died during course of therapy. The cause of death in these patients was septicaemia with severe dehydration. Two patients were lost to follow up. The patients were hospitalized and administered medicines for an average duration of $4.49 \pm 2.09$ days with a range of 1 day to 15 days.

A total 776 drugs were prescribed as 781 formulations in these inpatients. A switch from intravenous to oral formulation was observed in 5 cases during therapy. This was attributed to an improvement in the patients' condition. The mean number of drugs prescribed per patient was $7.53 \pm 1.87$ (range 3 to 15). Seven drugs were prescribed in $28 \%$ patients. Out of the various drugs prescribed, 245 (31.6\%) were rehydration fluids like ORS (102), ringer lactate (71) and, isolyte-P (71), normal saline (1). Other frequently prescribed drugs were antimicrobials (198; 25.5\%) followed by zinc $(98 ; 12.6 \%)$ and nutritional supplements $(69 ; 8.9 \%)$. Other drugs prescribed included anti-emetics (64), haematinics (48), antipyretics (24), anticonvulsants, bronchodilators, corticosteroids and other electrolytes like magnesium chloride, potassium chloride and calcium chloride [Figure 1].

A total of 257 (33.11\%) fixed dose combinations (FDCs) were prescribed. Among these 183 (71.20\%) were rational FDCs like amoxicillin + clavulanic acid, ORS and cotrimoxazole, while $74(28.79 \%)$ were irrational FDCs like nutritional supplements and ibuprofen with paracetamol. Out of the 781 drug formulations prescribed, $329(42.1 \%)$ were prescribed by their brand names, while $57.9 \%$ were prescribed by their generic names. Zinc acetate was most frequently prescribed by its brand name. Among the brand formulations, $227(69 \%)$ were dispensed by private pharmacies while $102(31 \%)$ were dispensed by the hospital pharmacy. Out of the 781 formulations prescribed, $481(61.6 \%)$ were oral formulations and

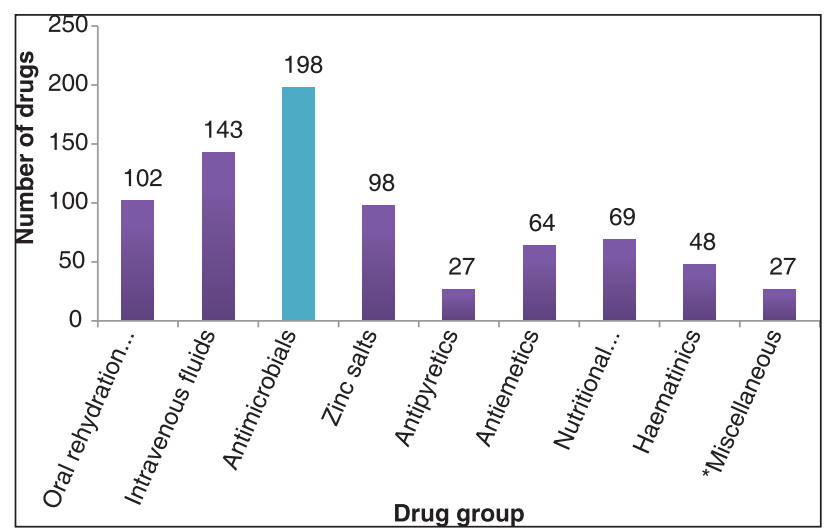

Figure 1: Drugs prescibed in pediatric inpatients of diarrhoea at CHA $(n=776)$
$298(38.2 \%)$ were intravenous injections including vials (154; $51.9 \%)$ and pints $(143 ; 48.15 \%)$. Two drugs were administered as nebulisers. Syrup $(307 ; 63.8 \%)$ followed by powders $(107 ; 22.2 \%)$ and tablets $(67 ; 13.9 \%)$ were the common oral formulations prescribed.

Out of 103 inpatients, 71 patients received ringer lactate (RL) and normal saline, which was considered rational since intravenous rehydration fluids are considered the primary treatment of diarrhea with severe dehydration and in those with mild and moderate dehydration who are unable to take adequate ORS within $4 \mathrm{~h}$. Two patients suffering from severe dehydration were administered Isolyte $\mathrm{P}$ as primary rehydration fluid instead of $\mathrm{RL}$, which was not appropriate. Isolyte $\mathrm{P}$ was additionally administered in 71 inpatients. The doses and frequency of all the intravenous rehydration fluids and oral rehydration fluids were appropriate and as per the IAP guidelines. A total of 102 formulations of ORS were administered in the right dose and duration soon after the severity of dehydration and diarrhea abated.

Antimicrobials were prescribed to all inpatients (100\%). Most inpatients $(60 ; 58.3 \%)$ received two antimicrobials during their hospital stay. The average number of antimicrobials prescribed per patient was $1.92 \pm 0.67$ (range 1 to 4 ). Twelve different antimicrobials were prescribed; among these cefotaxime (68) was the most prescribed followed by cotrimoxazole (55) and amoxicillin + clavulanic acid (25) [Figure 2]. The antimicrobials that accounted for more than $90 \%$ of the total antimicrobials used (Drug Utilization (DU) 90\%) are listed in Table 2 .

The appropriateness of antimicrobial usage was evaluated using modified Kunin's criteria and IAP guidelines for treatment of

\begin{tabular}{|c|c|}
\hline Antimicrobial & Number of prescriptions (\%) \\
\hline Cefotaxime & $68(34.34)$ \\
\hline Cotrimoxazole & $55(27.78)$ \\
\hline Amoxicillin+ clavulanic acid & $25(12.63)$ \\
\hline Doxycycline & $15(7.57)$ \\
\hline Ceftriaxone & $12(6.06)$ \\
\hline Ofloxacin & $6(3.03)$ \\
\hline Total & $181(91.41)$ \\
\hline
\end{tabular}

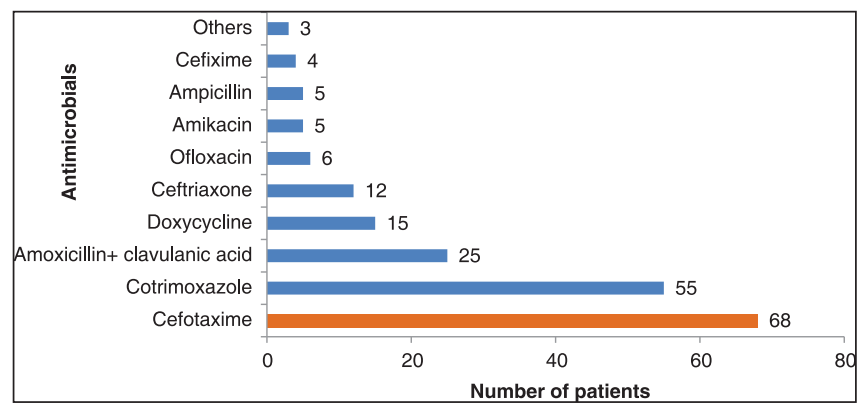

Figure 2: Antimicrobials used in pediatric inpatients of diarrhoea at $\mathrm{CHA}(n=198)$ 
diarrhea. Analysis of case records showed that antimicrobials were actually indicated in $40(38.83 \%)$ patients (17 patients required one antimicrobial and 23 patients required two) as per the recommended guidelines. Among 40 (38.83\%) inpatients who required antimicrobials, the use was appropriate only in $13(12.62 \%)$ patients (category I and II), while it was inappropriate in $27(26.21 \%$ ) patients (category III and IV). The use of antimicrobials was not necessary in $63(61.17 \%)$ patients (category V) [Table 3].

Ninety eight $(12.63 \%)$ zinc preparations (zinc acetate) were prescribed in $95.15 \%$ inpatients. All 98 prescriptions of zinc salts were considered as rational as per IAP and WHO guidelines.

The rationality of the prescriptions was also evaluated in reference to the WHO core indicators. It was observed that polypharmacy (7.53 \pm 1.87 drugs per encounter) was widely practiced. Antimicrobials and parenteral drugs (injections) were prescribed to all the patients. Nearly $57.9 \%$ drugs were prescribed by their generic name. More than $65 \%$ of the drugs prescribed were included in the National Essential Medicines List (EML) 2011 and WHO EML 2010 [Table 4].

An analysis of the ADRs observed in the patients showed that maculopapular rash was reported in a $5 \mathrm{~m}$ old male child due to cotrimoxazole use. The ADR was non-serious in nature. Patient recovered within a day after the drug was withdrawn. Causality assessment was carried out using WHO-UMC and Naranjo's causality assessment scales and cotrimoxazole was the probable drug causing this ADR. The ADR was not severe and not preventable. Total cost incurred to treat the ADR was Rs 28.30.

The average hospital expenditure incurred per patient per day was Rs 527.29. Considering the average duration of hospitalization of 4.49 days, the average hospital expenditure per inpatient was Rs 2367.53. The average cost of drugs prescribed per inpatient was Rs 212.46, while the average cost of medical supplies was Rs 20.55. Average cost of transportation per inpatient was Rs 94.17. Hence; the average total direct cost per inpatient amounted to Rs 2694.71. The average indirect cost per inpatient calculated as the loss of wages of parents/guardians per patient was Rs 470.10 . Therefore the economic impact of diarrhea was Rs 3164.81 per inpatient. The total economic impact of diarrhea in these patients calculated over a period of 18 months was Rs. 3,25,975.43 for 103 inpatients.

\section{DISCUSSION}

Each year, an estimated 2.5 billion cases of diarrhoea occur in children under five years of age and 12 million of them die in developing countries. ${ }^{[10]}$ The WHO and Indian Academy of Pediatrics have recommended guidelines for its treatment emphasizing early rehydration therapy and restrictions on use of drugs like antimicrobials and anti-diarrhoeals. In spite of guidelines, misuse of drugs like antimicrobials, anti-diarrhoeal etc. has been observed in various studies hence, the present study was undertaken.

It was observed that majority of the patients were males and below one year of age, which was also seen in a study conducted in Chennai, ${ }^{[11]}$ the Leeds study ${ }^{[12]}$ and the USA study. ${ }^{[13]}$ Usually most children are weaned from breast feeding at an age of 4 to 6 months. The possibility of infection by faeco-oral route is more likely during this period because of improper and unhygienic feeding practices. Further, while maternal antibodies are declining over this period, the child is yet to develop its own defenses against infections. ${ }^{[14]}$ While the predominance of diarrhoea in male children cannot be explained, it is assumed that the male children were likely to be brought to the hospital for treatment that the females. This is an unfortunate but common practice in India. A follow-up observational study in Kolkata, ${ }^{[15]}$ India found that boys with diarrhoea were more likely to be given oral rehydration fluids than girls, and were more likely to be taken to qualified health professionals for treatment. Most inpatients (78.84\%) were fully immunized as per the National immunization schedule. This reflects a general awareness among the caregivers about immunization and a good functional immunization program for children by health care providers.

Severe malnutrition PEM Grade III and IV was observed among 5 $(4.8 \%)$ and $4(3.8 \%)$ patients respectively in our study. A Chennai

\begin{tabular}{|c|c|c|}
\hline Kunin's criteria & No of patients (\%) & Justification \\
\hline $\begin{array}{l}\text { Criteria I - Agree with the use of antimicrobial } \\
\text { therapy, the protocol is appropriate. }\end{array}$ & $6(5.8)$ & - \\
\hline $\begin{array}{l}\text { Criteria II - Agree with the use of antimicrobial } \\
\text { therapy, the protocol is probably appropriate but } \\
\text { a microbiology report is missing to classify the } \\
\text { protocol in another category. }\end{array}$ & $7(6.8)$ & $\begin{array}{l}\text { Microbiology testing was performed, but report } \\
\text { was inconclusive. However the protocol was } \\
\text { appropriate }\end{array}$ \\
\hline $\begin{array}{l}\text { Criteria III - Agree with the use of antimicrobial } \\
\text { therapy, but a different antimicrobial is preferred. }\end{array}$ & $27(26.21)$ & $\begin{array}{l}\text { Too many antimicrobials were prescribed } \\
\text { concomitantly; the combination of antimicrobial } \\
\text { was not synergistic or antimicrobial cover was } \\
\text { inadequate in some cases }\end{array}$ \\
\hline $\begin{array}{l}\text { Criteria IV - Agree with the use of antimicrobial } \\
\text { therapy but a modified dose, interval, duration or } \\
\text { route of administration is preferred. }\end{array}$ & $0(0)$ & - \\
\hline $\begin{array}{l}\text { Criteria V - Disagree with the use of antimicrobial } \\
\text { therapy, administration is unjustified. }\end{array}$ & $63(61.17)$ & $\begin{array}{l}\text { Infections viral in origin, Antimicrobials not } \\
\text { required }\end{array}$ \\
\hline
\end{tabular}


study ${ }^{[1]}$ found that $24(1.4 \%)$ patients suffered from PEM Grade IV. These finding reiterate that PEM and diarrhoea are interrelated and the management of diarrhoea in these patients should also take this fact into consideration.

The inpatients in this study were followed up till discharge from hospital. The average duration (4.49 \pm 2.09 days) of hospital stay was similar to a study conducted in pediatric inpatients at a tertiary care hospital, Nepal. ${ }^{[16]}$ The average number of drugs/injections per encounter is an important index in prescribing practices. ${ }^{[17]}$ The values in our study are higher than the recommended limit of two drugs per encounter and the international average of 2.2 drugs per prescription. ${ }^{[18]}$ Polypharmacy was evident in the study as in $27 \%$ of inpatients; seven drugs were concomitantly prescribed. A cluster survey conducted in under five children of acute diarrhoea at Bangladesh found that the average number of drugs prescribed per patient was 1.5; a figure much lower than that found in our study ${ }^{[19]}$ while a Nepal study ${ }^{[16]}$ found that the average number of drugs per pediatric inpatient was $4.5 \pm 3.7$. Hence, it is evident that the practice of polypharmacy is prevalent in our setup; thereby suggesting irrational prescribing practice in this regard. Polypharmacy practice is well known to be associated with drug related adverse drug reactions, medication errors, clinically significant drug interactions and an increased rate of admissions to hospital. The reasons for this practice could range from lack of accuracy/confidence in diagnosis or lack of awareness of the various treatment guidelines and needs further evaluation.

\begin{tabular}{|c|c|}
\hline WHO Core indicators & Inpatients $(n=103)$ \\
\hline $\begin{array}{l}\text { Number of drugs prescribed per } \\
\text { encounter (mean + SD) }\end{array}$ & $7.53 \pm 1.87$ \\
\hline $\begin{array}{l}\text { Percentage of drugs prescribed by } \\
\text { generic name }\end{array}$ & 57.87 \\
\hline $\begin{array}{l}\text { Percentage of encounters } \\
\text { resulting in the prescription of an } \\
\text { antimicrobial }\end{array}$ & 100 \\
\hline $\begin{array}{l}\text { Percentage of encounters resulting } \\
\text { in the prescription of an injection }\end{array}$ & 100 \\
\hline $\begin{array}{l}\text { Percentage of drugs prescribed } \\
\text { from National Essential Medicines } \\
\text { List (EML) } 2003\end{array}$ & 66.97 \\
\hline $\begin{array}{l}\text { Percentage of drugs prescribed } \\
\text { from WHO EML } 2010\end{array}$ & 65.3 \\
\hline
\end{tabular}

A total 776 drugs were prescribed in 103 inpatients. Rehydration fluids and antimicrobials were the most commonly prescribed drug groups. No anti-diarrhoeals agents were prescribed to these patients. The average number of antimicrobials prescribed per inpatient in our study was $1.92 \pm 0.67$ with a range of 1 to 4 antimicrobials. Majority inpatients $(58 \%)$ received two antimicrobials during their hospital stay. When compared with other studies conducted in central Thailand ${ }^{[20]}$ and Chennai, ${ }^{[1]]}$ it was observed that antimicrobials were prescribed significantly more in our study $(P<0.05)$. Zinc salts were prescribed more often in our study as compared to that reported in the Chennai study $(P<0.05)$ [Table 5]. Ceftriaxone was the most commonly used antimicrobial followed by amikacin. The use of antimicrobials was significantly higher in our study than in other studies mentioned above.

While all patients in our study were prescribed antimicrobials, they were indicated only in $38.8 \%$ patients with cholera, severe malnutrition, a positive stool culture, septicemia, and in children less than 3 months. Only $12.6 \%$ patients in our study received antimicrobials appropriately. Inappropriate use of antimicrobials in children with diarrhea has been reported by other researchers as well. A cross-sectional study conducted in 424 patients of diarrhoea at central region province of Thailand observed that only $27.4 \%$ cases were appropriately managed with antimicrobials and $72.6 \%$ were inappropriately treated as per the guidelines. ${ }^{[20]}$ Injudicious use of antimicrobials observed in our study may be due to factors like doubtful diagnosis and underuse of laboratory investigations resulting in an empirical use of antimicrobials. While the exact reason needs further evaluation, this injudicious use of antimicrobials needs attention and appropriate interventions for rectification.

Appropriate use of ORS as well as intravenous rehydration fluids as per WHO and IAP guidelines was observed in most cases, except in two cases where Isolyte P was used as replacement fluid in severe dehydration rather than RL. Isolyte P is recommended in literature as a maintenance fluid in pediatric patients; however the WHO and IAP guidelines do not recommend this fluid for maintenance fluid therapy. A questionnaire based study conducted in emergency pediatric department at New Zealand and Australia found that $86 \%$ of physicians would use intravenous fluids in severe dehydration, most commonly half normal saline (with glucose) and normal saline. ${ }^{[21]}$ Zinc acetate was prescribed in $95.2 \%$ inpatients which was better than the Chennai study (65\%). A questionnaire based national survey found that $16.9 \%$ of prescribers prescribe zinc supplements for treatment of diarrhoea. ${ }^{[22]}$ Zinc supplements

\begin{tabular}{|c|c|c|c|}
\hline Parameter & Our study $(n=103)(\%)$ & $\begin{array}{c}\text { Howteerakul N et al } \\
\text { (Central Thailand) })^{[20],} 2004(n=149)(\%)\end{array}$ & $\begin{array}{c}\text { Balasubramanian S et al } \\
\text { (Chennai, India) })^{[11]}, 2007(n=1700)(\%)\end{array}$ \\
\hline Age less than 1 year & 43.68 & 45 & 49.88 \\
\hline Males & 54.37 & 56 & NA \\
\hline $\begin{array}{l}\text { Patients prescribed } \\
\text { antimicrobial }\end{array}$ & 100 & $92^{*}$ & $41.8^{*}$ \\
\hline Patients prescribed ORS & 99.02 & NA & NA \\
\hline Patients prescribed zinc salts & 95.15 & NA & $65^{*}$ \\
\hline
\end{tabular}

${ }^{*} p<0.05$ considered significant using Chi-square test 
are recommended in patients of diarrhoea because it reduces the severity and frequency of diarrhoea.

Certain good prescribing practices have been observed in our study. For example, more than $70 \%$ of FDCs like ORS, cotrimoxazole and amoxicillin + clavulanic acid etc. used in patients are included in EML (National and WHO). A study conducted in pediatric inpatients at a tertiary care hospital in Nepal found that FDCs constituted $6.9 \%$ of all drug used. ${ }^{[16]}$ Prescription of single drug formulations instead of FDCs may make better prescribing sense in terms of cost and safety. Generic prescribing and use of essential medicines are important parameters to evaluate the rational use of medicines (RUM). It was observed in this study that nearly half of the drugs in indoor patients were prescribed by their generic names. Our study fares similar or better than other studies, in this regard. This is attributed to the fact that most drugs supplied by hospital pharmacy are generic products, which are likely to be chosen by prescribers. Brand drugs were also prescribed in our study. In spite of availability of medicines from the hospital pharmacy, nearly $34 \%$ of inpatients had purchased drugs from commercial pharmacies. This practice suggests a gap in communication between the hospital pharmacists and the prescribers regarding the list of available drugs. In the present study $65.3 \%$ of drugs prescribed to inpatients were from the WHO Essential Medicine List, while $67 \%$ of drugs were from National Essential Medicine List 2003. Essential drugs offer a cost-effective solution to many health problems in a developing country. Knowledge, availability and access to drugs in the EML promote rational therapeutics.

The higher cost of therapy incurred in our study as compared to previous studies ${ }^{[23,24]}$ may be attributed to increasing cost of drugs and health care facilities. A difference in the healthcare policies between our country and other countries (reimbursements, higher monetary value for productivity) and the prospective nature of this study may also account for this discrepancy. However, simple measures like curtailing polypharmacy, generic prescribing, appropriate selection of drugs and their formulations and definitive instead of empirical therapy can minimize the cost burden in these patients.

One ADR was reported to drugs prescribed for acute gastroenteritis with severe dehydration in our study. A review study of ADRs in pediatric patients estimated an overall incidence of ADRs in inpatients to be $9.53 \%$ and that in outpatients to be $1.46 \% \cdot{ }^{[25]} \mathrm{A}$ rather low incidence of $\mathrm{ADR}(0.9 \%)$ in inpatients was reported in our study as compared to the above studies. Under-reporting of minor or non serious ADRs like nausea or vomiting which were either not detected or reported could contribute to low reporting.

The findings of this study suggested that a relatively rational approach to oral and parenteral rehydration therapy and zinc but inappropriate and overuse of antimicrobials, nutritional supplements and irrational FDCs in our study. However; further studies in this area are warranted before suggesting ways to reduce the economic impact of the disease. This is important for a centre like ours with a huge patient population, most of whom belong to the lower and lower middle socioeconomic groups. Some of the recommendations that may be made based on this study include reducing polypharmacy and empirical prescribing, encouraging generic prescribing and appropriate choice of drugs and their formulations.

\section{REFERENCES}

1. Bhargava R, Uppal S. Use of cold medications for upper respiratory tract infections in children. Pharmacoepidemiol Drug Saf 2001;10:323-7.

2. World Health Organization. The treatment of diarrhoea: A manual for physicians and other senior health workers. $4^{\text {th }}$ rev. Department of Child and Adolescent Health and Development, Geneva: World Health Organization; 2005. p. 4. Available from: http://whqlibdoc.who.int/ publications/2005/9241593180.pdf. [Last accessed on 2012 Nov 11].

3. National Commission on Macroeconomics and Health. Burden of Disease in India. New Delhi: Ministry of Health and Family Welfare; 2005. Available from: https://nrhm-mis.nic.in/ui/who/PDF/ Report $\% 20$ of $\% 20$ the $\% 2$ National\%20Commission $\% 20$ on $\% 20$ Macroeconomics\%20and\%20Health\%202005.pdf. [Last accessed on 2012 Sep 28].

4. Gupte S, editor. The Short Textbook of Pediatrics. $10^{\text {th }}$ ed.. New Delhi: Jaypee Publishers; 2004. p. 366.

5. Park K, editor. Park's Textbook of Preventive and Social Medicine. $18^{\text {th }}$ ed. Jabalpur: Bhanot Publishers; 2005. p. 517.

6. Ghai OP, Paul VK, Bagga A, editors. Essential Pediatrics. $7^{\text {th }}$ ed. New Delhi: CBC Publishers; 2009. p. 72.

7. Vlahovic-Palcevski V, Francetic I, Palcevski G, Novak S, Abram M, Bergman U. Antimicrobial use at a university hospital: Appropriate or misused? A qualitative study. Int J Clin Pharmacol Ther 2007;45:169-74.

8. Bhatnagar $\mathrm{S}$, Wadhwa $\mathrm{N}$. Recent trends in the management of acute watery diarrhea in children. In: Bavdekar A, Matthai J, Sathiyasekaran M, Yachha SK, editors. IAP specialty series on Pediatric Gastroenterology. New Delhi: Jaypee Publishers 2008. P. 37-42.

9. Sanchez LA. Pharmacoeconomics. In: Dipiro JT, Talbent RL, editors. Pharmacotherapy. A pathophysiological approach. $6^{\text {th }}$ ed. New Delhi: The McGraw-Hill; 2002. p. 1-16.

10. United Nations Children's Fund. Diarrhoea: Why children are still dying and what can be done. Available from: http://www.unicef.org/media/files/ Final_Diarrhoea_Report_October_2009_final.pdf. [Last accessed on 2012 Dec 15].

11. Balasubramanian S, Ganesh R. Prescribing pattern of zinc and antimicrobials in acute diarrhoea. Indian Pediatr 2008;45:701.

12. Conway SP, Phillips RR, Panday S. Admission to hospital with gastroenteritis. Arch Dis Child 1990;65:579-84.

13. Tieder JS, Robertson A, Garrison MM. Pediatric hospital adherence to the standard of care for acute gastroenteritis. Pediatrics 2009;124;1081-7.

14. World Health Organization (India), 1985. Available from: http://www.whoindia. org/LinkFiles/GPP_Rational_Use_of_Medicines.pdf. [Last accessed on 2012 Sep 30, cited on 2009 Aug 19].

15. Pandey A, Sengupta PG, Mondal S, Gupta D, Manna B, Ghosh S, et al. Gender differences in healthcare-seeking during common illnesses in a rural community of west Bengal. India J Health Popul Nutr 2002;20:306-11

16. Shankar PR, Upadhyay DK, Subish P, Dubey A, Mishra P. Prescription patterns among paediatric inpatients in a teaching hospital in Western Nepal. Singapore Med J 2006;47:261-4.

17. Karande S, Sankhe P, Kulkarni M. Patterns of prescription and drug dispensing. Indian J Pediatr 2005;72:117-21.

18. Mummad J. Audit of paediatric prescriptions for the common paediatric problems. Pak J Med Sci 2007;23:932-5.

19. Alam MB, Ahmed FU, Rahman ME. Misuse of drugs in acute diarrhea in under-five children. Bangladesh Med Res Counc Bull 1998;24:27-31.

20. Howteerakul N, Higginbotham N, Dibley MJ. Antimicrobial use in children under five years with diarrhea in a Central Region Province, Thailand. Southeast Asian J Trop Med Public Health 2004;35:181-7.

21. Schutz J, Babl FE, Sheriff N, Borland M. Emergency department management of gastro-enteritis in Australia and New Zealand. J Paediatr Child Health 2008:44:560-3. 
22. Alameddine A, Mourad S, Rifai N. Management of acute gastroenteritis in healthy children in Lebanon - A national survey. North Am J Med Sci 2010;2:512-7.

23. Zimmerman CM, Parashar JS, Umesh D, Lynn T, Holman, Robert C, et al. Cost of diarrhea-associated hospitalizations and outpatient visits in an insured population of young children in the United States. Pediatr Infect Dis J 2001;20:14-9.

24. Mendelsohn A, Asirvatham JR, Mwamburi DM, Sowmynarayanan TV, Malik V, Muliyil JP, et al. Estimates of the economic burden of rotavirusassociated and all cause diarrhoea in Vellore, India. Trop Med Int Health 2008;13:934-42.

25. Impicciatore P, Choonara I, Clarkson A, Provasi D, Pandolfini C, Bonati
M. Incidence of adverse drug reactions in pediatric in/outpatients: A systematic review and meta-analysis of prospective studies. $\mathrm{Br} \mathrm{J}$ Clin Pharmacol 2001;52:77-83.

How to cite this article: Panchal JR, Desai CK, lyer GS, Patel PP, Dikshit RK. Prescribing pattern and appropriateness of drug treatment of diarrhoea in hospitalised children at a tertiary care hospital in India. Int J Med Public Health 2013;3:335-41.

Source of Support: Nil, Conflict of Interest: None declared. 